\title{
Estimation of Optimal Chest Compression Depth based on Chest Computed Tomography in Thai Patients.
}

Nalinas KHUNKHLAI ${ }^{1}$ Pakkaphon AIEMPAIBOONPHAN ${ }^{2}$ Rathachai KAEWLA ${ }^{3}$ Pinporn JENJITRANANT ${ }^{3}$ Krisna DISSANEEVATE $^{4}$ Pairoj KHRUEKANCHANA $^{2}$ ${ }^{1}$ Thai Resuscitation Council ${ }^{2}$ Depeartment of Emergency Medicine and Narenthorn EMS Centre, Rajavithi Hospital, Bangkok,THAILAND ${ }^{3}$ Department of Diagnostic and Therapeutic Radiology, Ramathibody Hospital, Mahidol University, Bangkok THAILAND `Department of Radiology, Rajavithi hospital, Bangkok,
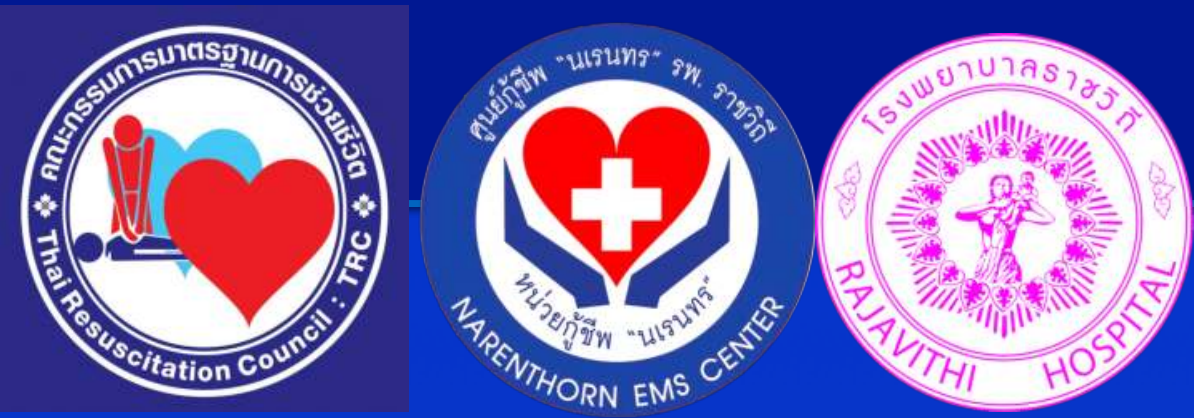
THAILAND

\section{BACKGROUND}

Many studies evaluated chest internal diameters using radiological assessment to estimate the better chest compression depth and position during cardiopulmonary resuscitation but the results varied among ethnic groups. This study aimed to identify the chest compression depth across BMI groups in Thai patients when simulated compression depth was delivered in $1 / 2,1 / 3,1 / 4$ of external chest(AP) antero-posterior diameter (EAPD) and $5-6 \mathrm{~cm}$ depth according to the current guidelines.

\section{METHODS}

A total of 421 consecutive chest computed tomography scans (male 50.8\%) were reviewed across BMI groups (BMI under 18.5, 18.5-24.99, 25-29.99, and over $30 \mathrm{~kg} / \mathrm{m} 2$ ) The external anteroposterior diameter (EAPD) were measured from the skin anteriorly at midlower half of sternum to the skin on the posterior thorax and will be used as an external marker for simulated chest

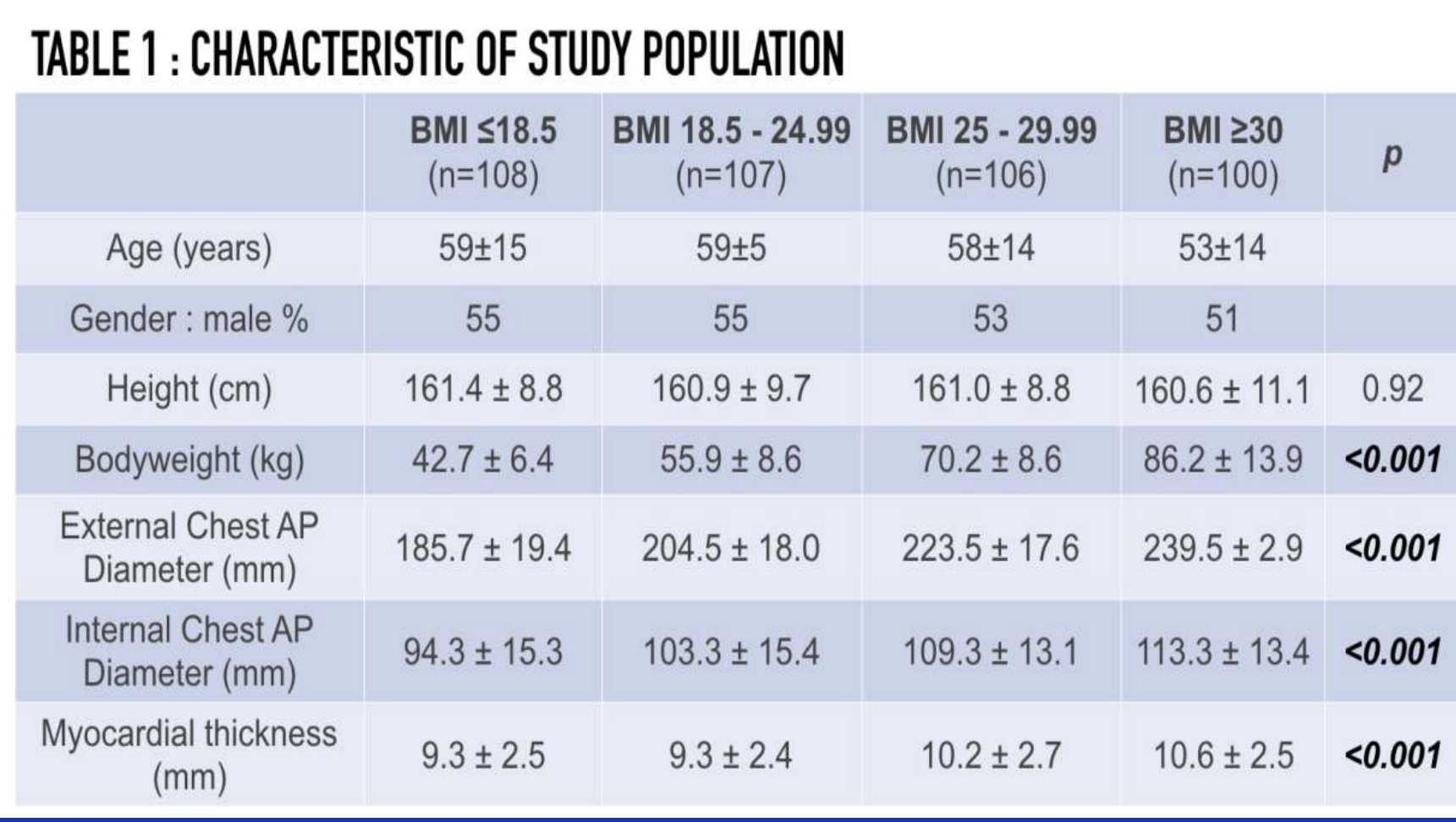

TABLE 2 : RESIDUAL CHEST DEPTH AT EACH COMPRESSION LEVEL ACROSS BMIS

\begin{tabular}{ll|l|l} 
BMI $\leq 18.5$ & BMI $18.5-24.99$ & BMI $25-29.99$ & BMI $\geq 30$
\end{tabular}

$(n=108) \quad(n=107) \quad(n=106) \quad(n=100)$

Compression $5 \mathrm{~cm} .(\mathrm{mm}) \quad 44.33 \pm 15.32 \quad 53.34 \pm 5.41 \quad 59.29 \pm 13.10 \quad 63.25 \pm 13.43<0.001$

\begin{tabular}{|l|l|l|l|l|l}
\hline Compression $6 \mathrm{~cm} .(\mathrm{mm})$ & $34.33 \pm 15.32$ & $43.34 \pm 5.41$ & $49.29 \pm 13.10$ & $53.25 \pm 13.43$ & $<0.001$
\end{tabular}

$\begin{gathered}\text { Compression } \\ 1 / 4 \text { of EAPD }(\mathrm{mm})\end{gathered} \quad 47.92 \pm 11.34 \quad 52.21 \pm 11.94 \quad 53.40 \pm 9.77 \quad 53.38 \pm 10.16 \quad<0.001$

\begin{tabular}{c|c|c|c|c|c}
\hline Compression & $32.45 \pm 10.18$ & $35.17 \pm 0.95$ & $34.77 \pm 8.86$ & $33.49 \pm 9.6$ & 0.16
\end{tabular}
The internal diameter (ID) were calculated from internal chest wall to surface of the cardiac wall. The Residual chest depth was calculated by ID minus simulated compression depth and targeted less than $20 \mathrm{~mm}$. The patients in conditions which may alter thoracic or cardiac anatomy (COPD, Cor pulmonale, ventricular hypertrophy) were excluded.

\section{RESULTS} BMls. Mean height in male $(166.53 \pm 0.92 \mathrm{~cm})$ and female $(155.22 \pm 0.57 \mathrm{~cm}$.) were recorded but there's no different across BMls in the same gender. The more patients' weight, the larger EAPD were identified ( $r$ 0.78). By simulated chest compression at lower half sternum, the compression depth at 1/3 of EAPD provided the best residual chest depth in all BMl groups $(32.45 \pm 10.18$ vs $35.17 \pm 10.95$ vs $34.77 \pm 8.86$ vs $33.42 \pm 9.60 \mathrm{~mm}$. for $B M l<18.5$ vs $18.5-24.99$ vs $25-29.99$ vs over 30 $\mathrm{kg} / \mathrm{m} 2$ respectively; $\mathrm{p}=0.16)$. The cardiac ventricle were best exposed at sternoxiphoid junction area but there's possible intra-abdominal organ injury identified. (Liver $34 \%$ of cases).

\section{CONCLUSIONS} the optimal compression depth in Thai population. The further clinical study may need to identify the association with survival outcomes.

Remark : The compression site which best direct expose and possible compress to left ventricular chamber is at xiphoid level. However, there are high possible intraabdominal organ injuries such as liver and spleen expose in the view, from $3.3 \%$ to $33.9 \%$. compression.
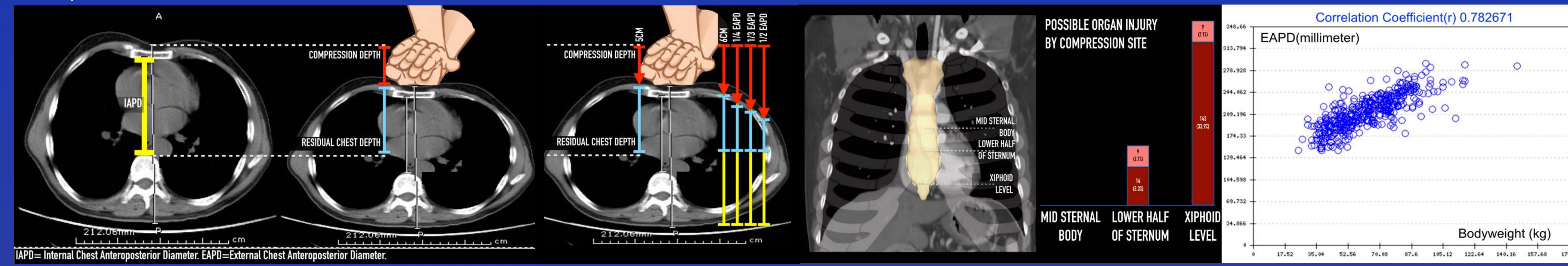

REFERENCE : Cha KC, Kim YJ, Shin HJ, Cha YS, Kim H, Lee KH et al. Optimal position for external chest compression during cardiopulmonary resuscitation: an analysis based on chest CT in patients resuscitated from

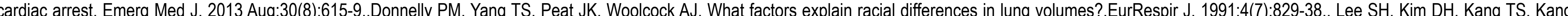
C Jeong JH Kim SC Kim DS. The uniform chest compression depth of $50 \mathrm{~mm}$ or greater rocommended by current guidelines is not appropriate for all adults. Am J Emerg Med 2015 Aug:33(8):1037-41. H Matsukubo I $\underline{\text { Matsuura, }} \underline{\mathrm{N} E n d o}$, J Asayama, T Watanabe. Echocardiographic measurement of right ventricular wall thickness. A new application of subxiphoid echocardiography. Circulation. 2015;131(24): 5535 .

Copyright $\odot 2017$ Nalinas KHUNKHLAI MD FTCEP: Pakkaphon AIEMPAIBOONPHAN 